\title{
Pensando uma estética feminista na arte contemporânea: diálogos entre a história e a crítica da arte com o feminismo
}

\author{
Dramatização dos corpos: arte contemporânea e crítica \\ feminista no Brasil e na Argentina
}

TVARDOVSKAS, Luana Saturnino.

São Paulo: Intermeios, 2015.

\begin{abstract}
Quando pensamos na intersecção entre feminismo e arte no Brasil, uma lacuna histórica ganha espaço. Lacuna que nos deixa sem palavras, que silencia nosso pensamento e revela uma carência preocupante sobre esse tema. Num momento histórico no qual o feminismo tem finalmente sido compreendido como um dos importantes protagonistas frente a discussões diversas sobre as diferenças culturais, étnicas, geracionais, de classe, de espécie e de gênero, nada mais justo que discutir esse protagonismo também no campo das artes visuais. É nesse contexto que o livro Dramatização dos corpos: arte contemporânea e crítica feminista no Brasil e na Argentina, da pesquisadora Luana Saturnino Tvardovskas mostra-se de extrema relevância.

No campo das artes visuais foi grande a influência do ativismo feminista, entre inúmeros/ as pensadores/as da arte contemporânea (Michel ARCHER, 2013; Eleanor HEARTNEY, 2002; Griselda POLLOCK, 1999) é comum e quase unânime o entendimento de que o debate feminista da década de 1960 imprimiu um tônus mais político à arte produzida até então. Questões ligadas às diferenças culturais, étnicas e de gênero passaram a ser fundamentais, desdobrando-se, inclusive, numa crítica institucional à própria arte que, por sua vez, teve que rever alguns preceitos que por séculos passaram incólumes. Entre esses preceitos cito a hierarquia que alocava as mulheres artistas como inferiores aos homens, tão inferiores a ponto de não merecerem um espaço na história da arte, tão inferiores a ponto de terem seus próprios corpos e imaginário criados e representados sob a ótica masculina.

Nesse contexto, e influenciadas pelo feminismo, várias artistas levantaram inúmeros questionamentos acerca da naturalizada dominação masculina na arte, fazendo ver o caráter excludente e discriminatório daquele estado de coisas. Entre as questões levantadas podemos pontuar: a predominância de artistas homens e a quase ausência de artistas mulheres na história da arte; a tácita e naturalizada desvalorização das mulheres artistas nesse cenário -
\end{abstract}


tanto por parte dos homens quanto das mulheres; e a escassa presença das mesmas nos circuitos oficiais de arte da década de 1960 e 1970 nesses dois países. Tal debate, encabeçado principalmente por artistas e críticas de arte situadas em Nova York nas décadas de 1960 e 70, reverbera de modo muito particular na América Latina. Nesse interim, além de nos ajudar a compreender as nuances e relações de poder envolvidas nesse processo, o presente livro nos fornece ferramentas para compreender o protagonismo do feminismo nos vários rumos que a arte contemporânea tomou a partir da década de 1960, no Brasil e na Argentina.

Nesse enredo, Tvardovskas não somente discute a já sabida necessidade e importância de incluir as mulheres artistas na história da arte, como traz à luz alguns aspectos que alinham a produção artística de inúmeras mulheres artistas aos debates e lutas feministas próprias do século XX. Considerando que o feminismo ainda é alvo de uma série de ataques que tentam minimizar sua relevância política, ética e social, penso ser de grande urgência entender o feminismo em sua pluralidade e cartografar os vários ecos dessa luta nos mais diferentes campos de conhecimento. É nesse sentido que o livro é uma rica contribuição para o campo da história e das artes visuais, posto que esboça uma leitura coerente e responsável sobre os encontros e diálogos entre a história e a crítica da arte com o feminismo.

Valendo-se de importantes teóricas e críticas feministas de arte como Griselda Pollock e Linda Nochlin, ainda pouco discutidas, conhecidas e traduzidas no Brasil, o livro nos introduz a discussão sobre arte e feminismo produzida nos EUA a partir da década de 1960. Feito isso, a autora aponta algumas das ressonâncias que essas discussões desencadearam também na produção crítica e artística do Brasil e da Argentina. Por mais que nas décadas de 1960 a 1990 não possamos localizar nesses países um movimento feminista organizado nas artes visuais, aprendemos com Tvardovskas que os ecos das lutas travadas além-mar se faziam ouvir também em terras latino-americanas. A autora pontua que no Brasil e em outros países da América Latina as ditaduras civil-militares interferiram diretamente no alcance e nos desdobramentos do movimento feminista como um todo. Apenas com o término desses regimes opressivos é que as discussões feministas conseguiram ganhar maior visibilidade na mídia através de um contexto social mais amplo - e também nas artes visuais (TVARDOVSKAS, 2015, 2013).

Por conta dessa conjuntura geopolítica, não encontramos no Brasil uma corrente de arte feminista tão bem demarcada como a norte-americana por exemplo. Mesmo porque, em países como o Brasil e a Argentina, a interseção entre arte e gênero se deu apenas tardiamente, e foi pautada, principalmente, pelas discussões pós-estruturalistas e pelo feminismo da diferença surgidos na década de 1970 (Rocío de la Villa ARDURA, 2008). Nesse sentido, podemos dizer que a relação entre arte e feminismo carece ainda de uma pesquisa genealógica completa que possa revisar a história e a crítica da arte na América Latina incluindo artistas mulheres a partir das chaves conceituais oferecidas pela primeira e pela segunda ondas do feminismo, por exemplo. O livro, portanto, figura entre os primeiros no Brasil a lançar bases para a construção de um pensamento sistematizado sobre o tema.

No segundo capítulo, por exemplo, encontramos um retrato do cenário artístico brasileiro a partir da década de 1970. Nele fica claro que poucas são as artistas mulheres brasileiras que se autodenominam feministas ou que consideram suas produções feministas. Menos identitárias, elas não se compreendem como um grupo e tampouco levantam a bandeira do feminismo. Ao invés de uma ênfase identitária, o que vemos nas artistas brasileiras é a incorporação de temas e questões levantadas pelos feminismos, uma poética feminista voltada para reinventar narrativas sobre o feminino e o masculino, a ironizar as práticas de poder e a desconstruir estereótipos misóginos (TVARDOVSKAS, 2015). Adentrando mais no cenário artístico desse período, é possível afirmar que a relação entre arte e feminismo no Brasil é menos identitária, mas não por isso menos feminista. 
Ser menos identitário, mas não menos feminista é um dos aspectos que merece ser mais bem discutido e compreendido. Juntamente com a autora, é possível pensar que, independentemente de se autodenominarem ou não feministas, o trabalho de muitas artistas mulheres carrega uma poética feminista posto que se alinha a uma postura ética, estética e política de resistência e criação de outras figurações para o corpo, o feminino e para a subjetividade. Além e aquém de uma identidade feminista, falamos, pois, de um posicionamento crítico-inventivo diante do mundo. Crítico posto que se opõe à lógica de controle biopolítico que opera sobre nossos corpos, desejos e subjetividade afim de docilizálos. Inventivo posto que resiste a essa lógica criando outros modos de ser e estar no mundo, outros modos de viver a relação que estabelecemos com nossos corpos, práticas e desejos.

Como bem aponta Margareth Rago (1998, p. 8), muitas mulheres, artistas ou não, mas principalmente aquelas que se identificam como feministas, têm criado "novos padrões de corporeidades, belezas e cuidados de si, propondo outros modos de constituição da subjetividade, ou o que bem poderíamos chamar de estéticas feministas da existência." Nessa perspectiva, seguindo a pista de Michel Foucault (1995), mais importante que descobrir o que somos é recusar o que somos, recusa que mobiliza também a criação do que somos. É nessa perspectiva, que Tvardovskas (2015) lança um olhar mais atento à criação artística de seis artistas contemporâneas: as brasileiras Ana Miguel, Rosana Paulino e Cristina Salgado; e as argentinas Silvia Gai, Claudia Contreras e Nicola Costantino.

De acordo com Silvia Bovenschen (1985) e Roberta Stubs (2015), uma possível estética feminista teria como característica fundamental a liberação da imaginação das mulheres, sendo esta uma das linhas que costuram os trabalhos das artistas acima citadas. Falamos, pois, do modo como a capacidade crítica/inventiva que caracteriza o movimento feminista como um todo, principalmente o feminismo pós-estruturalista, figura também nas artes visuais através de algumas tendências entre as quais citamos: a recuperação histórica das artistas mulheres; o uso do corpo de forma autônoma e com um cunho reivindicatório; a desconstrução de estereótipos; a inovação da técnica pela incorporação de atividades estritamente relacionadas ao universo feminino como o bordado e a costura, assim como a utilização de elementos pouco valorizados ligados ao cotidiano; e a preocupação combinada com as questões de gêneros, raças, etnias e classes sociais.

Vale acrescentar que uma estética feminista se caracteriza também por um elo indissociável entre arte e vida, entre arte e experiência e entre arte e produção de subjetividade. Elos que reforçam o entendimento de que a arte pode ser tanto um espaço de tensionamento e resistência social e política, quanto um espaço de produção de um outro ethos com a vida. É nesse enlaçamento entre arte e vida que podemos pensar a prática artística de inúmeras mulheres artistas enquanto uma estética feminista da existência que se posiciona diante da vida de maneira crítica e propositiva. Uma estética da existência que se afirma múltipla e ganha materialidade e visualidade na crítica cultural feminista que emana das imagens e das proposições das artistas brasileiras e argentinas aqui discutidas.

Por fim, utilizando chaves diversas e nômades para entender as mulheres em sua pluralidade, com Tvadovskas (2015) aprendemos que afirmar a multiplicidade ou as diferenças em sua infinita alteridade faz parte do projeto político e estético feminista. Projeto que figura nas artes visuais como um compromisso voltado para a renovação do imaginário social e cultural acerca do universo feminino. Cartografar as ferramentas conceituais que nascem do encontro entre os feminismos e as artes visuais possibilita que um "museu imaginário feminista", como quer a autora inspirada pelas contribuições de André Malraux (2000), ganhe corpo. Um imaginário feminista que se materializa na obra de inúmeras e inúmeros artistas contemporâneos que mesmo sem saber são herdeirxs de uma linhagem crítica feminista que ultrapassa barreiras identitárias posto que se faz presente enquanto crítica cultural, enquanto projeto ético, estético e político. 
Nesse sentido, um dos grandes méritos desse livro é inaugurar em nosso vocabulário, em nosso universo de referências e em nossa visualidade, conceitos e figuras de pensamento que incluam em nosso campo de significação essa crítica cultural feminista tão importante para os séculos XX e XXI. Para além de um acerto de contas com a história, que por muito tempo colocou a arte das mulheres no lugar de subalternidade, a autora articula 0 pensamento feminista contemporâneo com a crítica e a história da arte e nos oferece ferramentas conceituais para ressignificar a prática artística de inúmeras mulheres. Ferramentas conceituais fundamentais para compreender a produção artística da contemporaneidade que se faz indissociável das contribuições conquistadas no campo do feminismo.

\section{Referências}

ARCHER, Michel. Arte Contemporânea: uma história concisa. São Paulo: Martins Fontes, 2013.

BOVENSCHEN, Silvia. Existe uma estética feminista? In: ECKER, Gisela (Org.), Estética Feminista. Barcelona: Icara Editora, 1985.

ARDURA, Rocío de la Villa. "Durante El feminismo de la igualdad: Historiografía, teoría y prácticas artísticas". Exit Book: feminismo y arte de género, Madrid, n. 9, p. 24-29, 2008.

FOUCAULT, Michel. O sujeito e o poder. In: DREYFUS, Hubert L; RABINOW, Paul. Michel Foucault: uma trajetória filosófica (para além do estruturalismo e da Hermenêutica). Rio de Janeiro: Forense Universitária, 1995, p. 231- 249.

HEARTNEY, Eleanor. Pós-modernismo. São Paulo: Cosac Naify, 2002.

MALRAUX, André, O Museu Imaginário. Lisboa: Edições 70, 2000.

POLLOCK, Griselda. Differencing the Canon: Feminism and the History of Art. London: Routledge, 1999.

RAGO, Margareth. Epistemologia feminista, gênero e história. Masculino, feminino, plural. Florianópolis: Mulheres, 1998.

STUBS, Roberta. A/r/tografia de um corpo-experiência: arte contemporânea, feminismos e produção de subjetividade. 2015. Tese (Doutorado em Psicologia) Programa de PósGraduação em Psicologia, Universidade Estadual Paulista, Campus de Assis, São Paulo, Brasil.

TVARDOVSKAS, Luana Saturnino. Dramatização dos corpos: arte contemporânea e crítica feminista no Brasil e na Argentina. São Paulo: Intermeios, 2015.

"Tramas feministas na arte contemporânea brasileira e argentina: Rosana Paulino e Claudia Contreras". Artelogie, n 5, Octobre 2013. Disponível em: http://cral.in2p3.fr/ artelogie/spip.php?article246. Acesso em 20/01/2015.

[Recebida em 23/05/2017 e aprovada em 24/10/2017]

Roberta Stubs

Universidade Estadual de Maringá, PR, Brasil

Roberta Stubs (rostubs@yahoo.com.br) é Professora de Artes Visuais na Universidade Estadual de Maringá. Artista visual, psicóloga e Doutora em Psicologia e Sociedade pela Universidade Estadual Paulista Julio de Mesquita Filho (UNESP/Assis), possui graduação em Psicologia pela Universidade Estadual de Maringá (2005), especialização em Saúde Mental e mestrado em História da Educação pela mesma instituição. Suas pesquisas exploram o elo entre práticas artísticas, produção de subjetividade e estudos feministas, em interseção com os processos de subjetivação na contemporaneidade e as políticas inventivas da vida. 